\title{
Seven time-savers for early career researchers
}

\author{
Ho Manh Tung \\ Ritsumeikan Asia Pacific University \\ Beppu, Oita, Japan
}

September 6, 2020

I want to summarize my thought and rationales for certain things that I do, which I believe have given me a little bit more time for research each day. As an early career researcher, juggling between family and research duties can be difficult. Here is how I tackle this problem.

\section{Fasting:}

I have been very interested in time-restricted feeding (intermittent fasting) for over two years now. I have been practicing it quite often (Di Francesco, Di Germanio, Bernier, \& de Cabo, 2018). Most days I fast 14-16 hours (I stop eating or drinking anything that has any calories in it between 8 to $9 \mathrm{pm}$, then wait until lunch the next day). Since my second child was born, once a week, I have a fasting window of 20-22 hours. Without being tethered to eating like I am used to, it really gives me time each day, one or two hours more free time and clear-mindedness. I just have to make sure I drink enough water, then I am good.

Besides, it seems there is a promising area of longevity research related to fasting (Mattson, Longo \& Harvie 2017). If fasting prolongs life in humans as it has been demonstrated in animal subjects, it could clearly give each researcher a few more productive years. But that is for the future. What I am interested in is the present. And in 
the present, two benefits stand out for me: I have a bit more time every day and every week, and I feel more awake and hungrier, literally and metaphorically.

\section{Mindfulness meditation:}

Research shows that if your mind wanders very often, as Killingsworth and Gilbert said in a 2010 Science paper: "A wandering mind is an unhappy mind." One of the ways a wandering mind makes you unhappy is that once you lost your focus, it takes on average 25 minutes, maybe even more, to regain your focus, according to the paper on the cost of interrupted work (Mark, Gudith,\& Klocke, 2008). Mindfulness meditation, viewed in this way, is the ultimate time-saver. If you catch your mind starting to wander five times a day, that means you save yourself from 125 minutes of distraction a day. If you spend 10 minutes a day to practice formal meditation, this is one of the best return on investment.

Another thing meditation really helps is that it strengthens whatever the neural correlates for curiosity and nonjudgmental interest (Brewer, Davis \& Goldstein, 2013; Siegel, 2007). In the formal practice of meditation, you learn to pay as much attention as possible for as little. Usually, at the start, you learn to focus exclusively on your breath and notice every detail of this most mundane and seemingly boring activity. That means if you can be nonjudgmentally curious about boring things like your breathing pattern or the ambient sound background, you can become more attentive to ideas, which will be a great time-saver for research.

My mentor has taught me a lot in paying close attention to the connection among ideas, turning on your "ideas-radars" to benefit from serendipitous ideas coming your way - the "creative quantum," training your "mind-sponge" I think meditation helps these processes (Napier \& Vuong, 2013; Vuong \& Napier, 2014, 2015; Vuong, 2016).

Finally, meditation teaches you to take a step back from your current thoughts. We all know what it is like to be lost in thoughts without realizing you are. Being able to detach, to evaluate whether some patterns of thoughts are useful (at this moment) or not is a good mental tool to have at your disposal. As a researcher, I sometimes find myself overwhelmed and not sure what to do for a paper because of all the thoughts that come in 
telling me different ways to approach it. Thus, just being able to breathe and be aware of what emotions drive my thinking process makes me feel more clear-headed when writing.

\section{Podcasts, blinkist, and audiobooks:}

You can listen to podcasts, blinkists, and audiobooks while cleaning the dishes, taking the trash, or going for a jog. It is clearly a time-saver.

But I think it saves time in even a better sense: it helps the process of "sampling ideas." I often listen to authors discuss and especially debate their new books or their new journal articles. I come to know some of the influential concepts, people, and institutions in my field this way. Then if something becomes more relevant, I will invest in researching these concepts and ideas.

Recently, I've subscribed to Blinkist. This apps offers a short 15 minutes summaries of non-fiction books. There are so many book titles there, which serve me both for research and pleasure. When I find a book that I really like or podcasts and blinkists are not enough to make me understand it, I will search for the audiobook version to listen for it.

Here, if you apply the "mindsponge," the "3D methods creativity," and "ideasradar" principles, sampling ideas this way makes even more sense (Napier \& Vuong, 2013; Vuong \& Napier, 2014, 2015; Vuong, 2016).

\section{Wake up early:}

Mike Tyson, when he trains for a fight, he said he wanted to wake up super early and train so that he feels he has a mental advantage over his opponents. This, I think, can be applied to researchers. You want to wake up super early, jump start your day. By the time other people wake up and sluggishly start their day, you have already done some research and writing.

Since my second child, I kind of give up on working late. Of course, when it matters, I will pull myself together and stay up late and work, but only when necessary. I 
try to sleep around 6-7 hours per night: go to bed around $10 \mathrm{pm}$ and wake up at 4:30 am. My kids wake up around 7:30 that gives me 3 hours of working with a rested, clear head.

I think working late at night after a long day already working and doing all the house works is comparable to the overtraining of athletes. Your brain and body are spent at $10 \mathrm{pm}$, staying up another 3 hours. The situation is like pushing yourself to keep training after a long training session. You just need more rest, which the rest from 1-7:30 am will not do. Then as a parent, you don't want your kids to see you sluggishly waking up. I want my kids to wake up and already see me working and training. That gives me some mental advantage.

\section{Remove carbs and oily foods from your lunch:}

So I usually don't eat breakfast and drink a lot of water in the morning. At lunch, I try to only have some meat and veggies, and I only drink black coffee. I find myself always feel sleepy or lousy during the afternoon if, at lunch, I eat rice, bread, noodles, and anything oily. Clearly, if you don't feel sleepy or lousy, you can use your time better.

\section{Text readers of Microsoft Edge:}

This is a new feature in Microsoft Edge that I stumbled upon recently. You can open any PDF file by Edge, and then you can use the text readers for free. Sometimes, when I don't want to read a journal article, I will open it with Edge and let the machine read to me while I do something else, usually, house works.

\section{A decent amount of sleep and exercises:}

Then, of course, even if you are busy, try to get a decent amount of sleep and exercise. Good habits of sleep, diet, and exercises prevent you from having chronic stress, mood swings, and anxiety and more likely to make you more productive and creative in general (Doi, Minowa, \& Tango, 2003; Lupu, 2012). They prevent the vicious spiral from happening: You are stressed and anxious, it reduces your productivity, makes you even more stressed and anxious, which makes you unpleasant to everyone around, which 
makes you more stressed. General good health is often taken for granted, but once you are sick, all you want is to have your health back.

\section{References}

Brewer, J. A., Davis, J. H., \& Goldstein, J. (2013). Why is it so hard to pay attention, or is it? Mindfulness, the factors of awakening, and reward-based learning. Mindfulness, 4(1), 75-80.

Di Francesco, A., Di Germanio, C., Bernier, M., \& de Cabo, R. (2018). A time to fast. Science, 362(6416), 770-775.

Doi, Y., Minowa, M., \& Tango, T. (2003). Impact and correlates of poor sleep quality in Japanese white-collar employees. Sleep, 26(4), 467-471.

Killingsworth, M. A., \& Gilbert, D. T. (2010). A wandering mind is an unhappy mind. Science, 330(6006), 932-932.

Lupu, E. (2012). Physical activities as a manner of lifelong developing creativity. Procedia-Social and Behavioral Sciences, 46, 1893-1898.

Mark, G., Gudith, D., \& Klocke, U. (2008, April). The cost of interrupted work: more speed and stress. Proceedings of the SIGCHI Conference on Human Factors in Computing Systems, Montréal Québec Canada. (pp. 107-110). URL: https://www.ics.uci.edu/ gmark/chi08-mark.pdf

Mattson, M. P., Longo, V. D., \& Harvie, M. (2017). Impact of intermittent fasting on health and disease processes. Ageing Research Reviews, 39, 46-58.

Napier, N.K. \& Vuong, Q.H. (2013). Serendipity as a strategic advantage?. In Wilkinson (ed) Strategic Management in the 21st Century (pp. 175-199). Westport, CT: Praeger/ABC-Clio. DOI: 10.13140/2.1.3311.952. 
Siegel, D. J. (2007). Mindfulness training and neural integration: Differentiation of distinct streams of awareness and the cultivation of well-being. Social Cognitive and Affective Neuroscience, 2(4), 259-263.

Vuong, Q. H. \& Napier, N. K. (2014) Making creativity: the value of multiple filters in the innovation process. Int J Transitions and Innovation Systems, 3(4), 294-327. DOI: 10.1504/IJTIS.2014.068306.

Vuong, Q. H. (2016) Global mindset as the integration of emerging socio-cultural values through mindsponge processes: A transition economy perspective. In J. Kuada (ed.) Global Mindsets: Exploration and Perspectives (pp. 109-126). London: Routledge

Vuong, Q.H. \& Napier, N.K. (2015). Acculturation and global mindsponge: an emerging market perspective. International Journal of Intercultural Relations, 49, 354-367. DOI: $\underline{10.1016 / j . i j i n t r e 1.2015 .06 .003 .}$ 